\title{
Effect of Gum Arabic on Liver Function And Antioxidant Enzymes of Sprague-Dawley Rats
}

\author{
Mohammed Babiker ${ }^{1,4}$,Tarig Abbas ${ }^{1}$, Mohammed Elimam Ahamed \\ Mohammed ${ }^{2,3}$ \\ ${ }^{1}$ Faculty Of Medicine- University Of Al Neelain- Khartoum- Sudan \\ ${ }^{2}$ Department Of Chemistry- Faculty Of Science- King Khalid University- Saudi Arabia \\ ${ }^{3}$ Sudan Atomic Energy Commission- Khartoum-Sudan. \\ ${ }^{4}$ Department Of Clinical Biochemistry- Faculty Of Medicine- King Khalid University
}

\begin{abstract}
The aim of this study was to investigate the effect of twelve weeks Gum Arabic dose on the liver functions and some antioxidant enzymes activity of 10 Sprague-Dawley rats.

Methods: 10 normal Sprague-Dawley rats were fed one liter 10\% of gum Arabic solution daily for 12 weeks. As a control group another 10 rats were not fed with gum Arabic. On week twelve, blood samples were collected from each rat and all of them were killed and the liver was obtained. Some of the liver was homogenized and the supernatant was collected. The liver function tests (direct bilirubin, total bilirubin, albumin, total proteins, Asparate transaminase, alanine transaminase and alkaline phosphatase) were done using the blood samples and the supernatant of the homogenized liver was used to detect the activity of superoxide dismutase and catalase and to measure the concentration of glutathione and Malondialdehyde (MDA).

Results: the comparison of the mean values of the liver function tests showed the absence of significant variation between the liver function tests in the control and the gum Arabic fed rats. Concerning the antioxidant parameters, there was significant increase in the superoxide dismutase ( $p$-value $\leq 0.000)$, catalase ( $p$-value $=$ $0.043)$, glutathione $(p$-value $=0.004)$ and significant decrease in the MDA concentration $(p$-value $\leq 0.000)$. Conclusion: Daily gum Arabic dose for twelve weeks significantly affected the liver antioxidant activity of Sprague-Dawley rats.
\end{abstract}

Keywords: Sprague-Dawley rats. Antioxidant activity, liver function, gum Arabic.

\section{Introduction}

Gum Arabic or Acacia gum is a non viscous liquid collected from the exudates of Acacia senegal and Acacia seyal stems and branches. The gum Arabic is composed majorly of macromolecules (carbohydrates and proteins), minerals and amino acids. The major carbohydrates in gum Arabic are rhamnose, arabinose, galactose and glucuronic acid. It is rich in some amino acids such as hydroxyproline, serine, threonine, proline, leucine and histidine. Gum Arabic is a valuable source of four antioxidant minerals; copper, iron, manganese and zinc.

Gum Arabic has many beneficiaries in different fields including industrial sections such as textiles, cosmetics, ceramics, pharmaceutical and food. In the pharmaceutical field, gum Arabic is used as a vehicle for drugs. It is reported that the gum Arabic has an antioxidant activity and it has positive effect on the cure of different system abnormalities such as the urinary tract, cardiovascular and gastrointestinal [1,2]. Gum Arabic lowered the blood level of liver enzymes, total proteins and bilirubin. It also reversed the liver damging effect of gentamicin and alloxan $[3,4]$.

Some studies showed the effectiveness of gum Arabic as antioxidant material in food preservation $[5,6]$ and in animals and humans through increasing the concentration of antioxidant enzymes and decreasing the oxidizing molecules in different organs [7, 8]. With regard to the side effects of gum Arabic, some studies have reported the uncoupling of oxidative phosphorylation in the heart and liver [9], allergy and hypersensitivity [10, 11].The aim of this article was to investigate the effect of gum Arabic on the liver function and antioxidant activity of Sprague-Dawley rats. The liver functions tests conducted in this study were total proteins, albumin, direct bilirubin, total bilirubin, Aspartate transaminase (AST), Alkaline Phosphatase and Alanine Transaminase (ALT). The antioxidant enzymes studied were Super Oxide Dismutase (SOD) and catalase. The antioxidant related molecules measured were glutathione (GSH) and Malondaialdehyde (MDA).

\section{Material And Methods}

Study population: The subjects of this study were 20 Sprague-Dawley rats. They were divided to two groups; 10 rats each. The two groups were divided in cages; each cage contained 5 rats. Group one was control group and group two was fed gum Arabic for twelve weeks (three months). Each cage of group two rats were fed $500 \mathrm{ml}$ of $10 \%$ gum Arabic solution. 
Ethical clearance: This study was conducted after academic and ethical approval from the faculty of medicine at the University of Al Neelain- Khartoum, Sudan.

Sampling: On week twelve, $5 \mathrm{ml}$ of retro-orbital blood samples was obtained from each rat for the investigation of the liver function, after that, the rats were killed by decapitation and the liver was dissected and

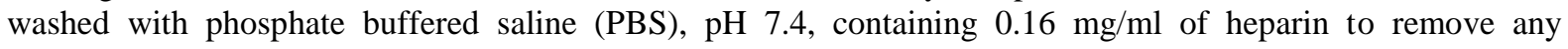
erythrocytes and clots.

$100 \mathrm{mg}$ of liver tissue was treated according to the instruction of each enzyme kit producing company.

Analysis Methods: the liver function was investigated according to instructions of the producing companies as follows; albumin (Albumin liquicolor REF 10560- Human- Germany), total proteins (Total protein liquicolor- REF 10570- Human- Germany), bilirubin (bilirubin D+ T liquicolor- Human- Germany), Aspartate transaminase (aspartate aminotransferase- REF EC 2.6.1.1- Human- Germany ), alanine transaminase (Alanine aminotransferase- REF EC 2.6.1.2- Human- Germany) and alkaline phosphatase (Alkaline phosphatase liquicolor- REF EC 3.1.3.1- Human- Germany).The antioxidant activity was determined according to the manufacturers information; catalase (abcam- ab83464 catalase assay kit- Colorimetric/Fluorometric), Superoxide dismutase (Cayman chemical- Superoxide Dismutase assay kit- item number. 706002), malondailadehyde (abcam- ab118970- Lipid Peroxidation (MDA) Assay kit - Colorimetric/ Fluorometric) and glutathione (SIGMA- ALDRICH- glutathione assay kit- catalog number. CS0260). The obtained results were analyzed by SPSS version 20. The mean values of the parameters of the two groups were analyzed using t- test.

\section{Rsults}

The range, mean and standard deviation of the liver function tests parameters in the two groups are presented in table.1. However, there was in significant increase in the concentration of the total proteins, albumin and alanine transaminase (Table.1, Fig.1, Fig.2). The direct bilirubin, aspartate transaminase and alkaline phosphatase were in significantly decreased (Table.1). The mean value of the total bilirubin is the same in the two groups. The superoxide dismutase, catalase and glutathione were significantly increased in the experimental group compared to the control group. The ranges of the superoxide dismutase and catalase in the control group was bellow their ranges in the experimental group. The malondailahdehyde (MDA) was significantly decreased in the experimental group compared to the control group (Table.1, Fig.1, Fig.2).

\section{Discussion}

Regarding the liver function tests we have registered that the gum Arabic dose $(500 \mathrm{ml}$ of $10 \%$ guma Arabic for each five rats every day for 12 weeks) leaded to insignificant decrease in the mean value of blood direct bilirubin, aspartate transaminase and alkaline phosphatase. Low levels of aspartate transaminase and alkaline phosphatase reflects a protective effect of gum Arabic on the liver and the bile duct cells. Concerning the AST and alkaline phosphatase, Said Said Elshama et al reached to the same finding of our study with a daily gum Arabic dose of 10 and $20 \mathrm{~g} \backslash \mathrm{kg}$ with iodomethacin for three, five and seven days [12]. Similar to our findings two studies stated that gum Arabic significantly decreased the blood concentration of aspartate transaminase $[3,4,13]$ However Abdelkareem and his research group [4] treated their rats with 15\% gum Arabic solution for 8 weeks while Ghassan F. Alubaidy [3] used mice in his experiment and a $10 \mathrm{~g} \backslash \mathrm{kg}$ body weight day for 8 days.

Unlike our finding a master thesis in the university of Khartoum registered increased level of AST and alkaline phosphatase by $0.5 \mathrm{~g} \backslash \mathrm{kg}$ body weight $\backslash$ rat $\backslash$ day gum Arabic dose for 45 days [14]. Similarly, a bile duct ligation in rats and a gum Arabic gum dose caused increased level of AST and alkaline phosphatase [15]. Tarkan KARAKAN [15] study used 3\% gum Arabic solution for six days, the dose was 100mg $\backslash \mathrm{kg}$ body weight daily. From the two contradicting results of gum Arabic on the liver enzymes it seems that low doses (100 and $500 \mathrm{mg} \backslash$ day ) are associated with high levels of AST and alkaline phosphatase while high doses (10 grams, $10 \%$ and $15 \%$ daily dose) leaded to low levels i.e. the gum Arabic effect on the liver function is dose dependant. We have found insignificant decrease in the direct bilirubin and an insignificant increase in albumin while the total bilirubin was not affected. Our result is scientifically acceptable since increased albumin concentration increases the bound bilirubin and decreases the free bilirubin. The $0.5 \mathrm{~g} \backslash \mathrm{kg} \backslash$ body weight dose of Sitona Satti Mohammed Ahmed and Asia Mohammed Elhassan [14] did not affect the albumin neither the total bilirubin. However, Ghassan F. Alubaidy revealed that the daily $10 \mathrm{~g} \backslash \mathrm{kg}$ body weight decreased the total bilirubin. In another study using human subjects, Chiang $M$ found that a mixture of sucrose acetate isobutyrate (SAIB), gum Arabic and orange juice did not affect the liver enzymes nor the direct bilirubin neither the total bilirubin [16].

We have found that our gum Arabic dose leaded to insignificant increase in total proteins and ALT. The results of the total proteins, albumin and the liver enzymes reflect the effect of gum Arabic on the synthesis of proteins either positively or negatively. Unlike our finding Sabahelkhier M. K et al concluded that 5\% of four different types of gum Arabic solutions on male albino rats did not affected the total blood proteins [17]. Another study on human subjects expressed the non effectiveness of $5 \mathrm{~g}$ / day gum Arabic dose on the total 
protein concentration [18]. Mahmoud Mai Makki found crude gum Arabic dose for Sudanese chronic renal failure patients decreased the total protein concentration by 13.2\% [19]. Ghassan F. Alubaidy [3] study showed that gum Arabic dose reduced the total protein concentration in the liver tissue of mice. Upon searching the literature we did not find any study that registered increase in total proteins and albumin due to gum Arabic treatment in animals or humans; the results were ranging between either no effect or decreased the total proteins or albumin $[3,12,16,17]$.

Regarding the Alanine transaminase (ALT) we have registered an insignificant increase in the blood level of ALT which reflect a cytotoxic effect of gum Arabic on liver cells. One study found that the ALT was increased by gum Arabic dose [14] and some studies, registered reduced level of ALT [3, 12, 13]. A third research group concluded that the gum Arabic has no effect of ALT activity in humans or animals [16].

The antioxidant parameters in our study were significantly affected. The positively affected parameters were the superoxide dismutase, catalase and glutathione while the only negatively affected parameter was the MDA. Similar to our findings Abdelkareem A.Ahmed and his research group mentioned that gum Arabic significantly increased superoxide dismutase, catalase, glutathione peroxidase and GSH. They also concluded that the gum Arabic dose significantly decreased the MDA [4]. Treatment of male rats with Trichloroacetate decreased the level of hepatic superoxide dismutase and catalase and increased the concentration of MDA. The trichloroactate toxicity was reversed by gum Arabic and peppermint oil [7, 20].

Ali BH conducted a study to investigate the antioxidant activity of three different doses of gum Arabic on kidney and liver of rats. He measured GSH and superoxide dismutase and his results indicated the absence of a significant effect of gum Arabic on the two parameters [21].

\section{Conclusion}

Daily $500 \mathrm{ml}$ of $10 \%$ gum Arabic solution for every 5 Sprague-Dawley Rats significantly increased the concentration of liver superoxide dismutase, catalase and glutathione and significantly decreased the concentration of MDA in liver tissues. The mentioned gum Arabic dose did not significantly affected all the studied liver function tests.

\section{References}

[1]. Mariana A Montenegro, María L Boiero Lorena Valle, Claudio D Borsarelli. Gum Arabic: More Than an Edible Emulsifier in: Products and Applications of Biopolymers, Edited by Dr. Johan Verbeek, InTech, 2012, pp 1- 26.

[2]. Badreldin H Ali, Amal Ziada, Gerald Blunden. Biological effects of gum arabic: A review of some recent research. Food and Chemical Toxicology., 47: 1-8 (2009).

[3]. Ghassan F Alubaidy. Study The Biochemical Effect of Gum Arabic in Liver Injury and Blood Serum of Mice Induce by Gentamycin. Bas.J.Vet.Res ., 12(1): 243- 252 (2013).

[4]. Abdelkareem A Ahmed, Jaafar S Fedail, Hassan H Musa, Asghar Ali Kamboh, Amal Z Sifaldin, Taha H Musa. Gum Arabic extracts protect against hepatic oxidative stress in alloxan induced diabetes in rats. Pathophysiology., 22: 189-194 (2015).

[5]. Ali Eskandari, Mokhtar Heidari, Mohammad hosein daneshvar, sadegh taheri. Studying effects of edible coatings of Arabic Gum and olive oil on the storage life and maintain quality of postharvest Sweet Lemon (Citrus Lemontta). Intl J Agri Crop Sci ., 7(4): 207 (2013).

[6]. Zuhair Radhi Addai, Aminah Abdullah, Sahilah Abd. Mutalib, Khalid Hamid Musa. Effect of Gum Arabic on Quality and Antioxidant Properties of Papaya Fruit during Cold Storage. Int.J.PharmTech Res., 5(4): 2854-2862 (2013).

[7]. Najla O Ayaz, Kholoud S Ramadan, Hoda E A Farid, Hanan S. Alnahdi. Protective role and antioxidant activity of arabic gum againsttrichloroacetate-induced toxicity in liver of male rats. Indian Journal Of Animal Research (2016). DOI:10.18805/ijar.10976.

[8]. Abdelkareem A Ahmed, Jaafar S Fedail, Hassan H Musa, Taha H Musa, Amal Z Sifaldin. Gum Arabic supplementation improved antioxidant status and alters expression of oxidative stress gene in ovary of mice fed high fat diet. Middle East Fertility Society Journal ., 21(2): 101- 108 (2016). http://dx.doi.org/10.1016/j.mefs.2015.10.001.

[9]. Bachman E and Zbinden G. Biochemical effects of chronically administered suspended agents on mitochondrial metabolism and hepatic mixed function oxidases in rat, mice and hamster, Arch. Toxicol. Suppl ., 1: 183-187 (1978).

[10]. Fötisch K, Fäh J, Wüthrich B, Altmann F, Haustein D, Vieths S. IgE antibodies specific for carbohydrates in a patient allergic to G.A. (Acacia senegal). Allergy., 53: 1043-1051 (1998).

[11]. Sander I, Raulf-Heimsoth M, Wiemer K, Kespohl S, Brüning T, Merget R. Sensitization due to G.A. (Acacia senegal): the cause of occupational allergic asthma or crossreaction to carbohydrates? Int. Arch. Allergy Immunol ., 141: 51- 56 (2006).

[12]. Said Said Elshama, Ayman El-Meghawry El-Kenawy, Hosam-Eldin Hussein Osman, Hamdi Mohamed Youseef. Amelioration of indomethacin systemic toxicity by gum arabic administration in adult albino rats. Int. J. Med. Plant Altern. Med ., 2(3): 32- 46 (2014).

[13]. Gamal el-din AM, Mostafa AM, Al-Shabanah OA, Al-Bekairi AM, Nagi MN. Protective effect of arabic gum against acetaminophen-induced hepatotoxicity in mice. Pharmacol Res., 48(6):631-5 (2003).

[14]. Sitona Satti Mohammed Ahmed and Asia Mohammed Elhassan. The Effect of Gum Arabic Supplements onSodium ValproateInduced Hepatotoxicity in Rats. Master Thesis, University of Khartoum, Khartoum, Sudan, 2010.

[15]. Tarkan KARAKAN, Mustafa KEREM, Mehmet C`NDORUK, Doruk ENGくN, Murat ALPER, Okan AKIN. PPAR-alpha agonist treatment increases trefoil factor family-3 expression and attenuates apoptosis in the liver tissue of bile duct-ligated rats. Turk $\mathrm{J}$ Gastroenterol ., 24 (2): 134-140 (2013). doi: 10.4318/tjg.2013.0605.

[16]. Chiang M, Gray K, Chappel CI. Effect of sucrose acetate isobutyrate (SAIB) ingestion on the hepatobiliary function of normal human male and female volunteers. Food Chem Toxicol., 36(2):141-4 (1998).

[17]. Sabahelkhier M K, Elfadil AG, Nagla A H, Esra S B, Rayan MY, Daa M O. Assessment of Toxicity and Influence of Three Types of Gum Arabic on Blood Glucose, Body Weight, Total Protein and Lipid Profile on Diabetic Rats. International Journal of Advanced Research .,1(6): 13-19 (2013). 
[18]. A A Ali, K E Khalid, K E Ali. The effect of gum Arabic oral treatment on the iron and protein status in chronic renal failure patients under regular hemodialysis in central Sudan. African Journal of Urology., 11(4): 268- 274 (2005).

[19]. Mahmoud Mai Makki. Regulation of some Health Indicators by Using Gum Arabic. PhD thesis science. Sudan University of Science and Technology, 2011. Available at: http://repository.sustech.edu/handle/123456789/3120. Acessed on 21 Dec 2016 at 9:09 AM.

[20]. Aly H M, Amal E Abd El- Kader, Amal M Abo El- Maaty, Hafiza A Sharaf. Andrological, oxidative stress and pathological effects of encapsulated peppermint oil with gum Arabic, Part 1. RJPBCS ., 7(3): 695- 704 (2016).

[21]. Ali BH. Does gum Arabic have an antioxidant action in Rat kidney. Ren Fail., 26(1): 1-3 (2004).

Table.1: The mean values, standard deviation (SD), range and the t- test result of the study parameters

\begin{tabular}{|c|c|c|c|c|c|}
\hline \multirow[t]{2}{*}{ Parameter } & \multicolumn{2}{|c|}{ Control group } & \multicolumn{2}{|c|}{ Experimental group } & \multirow[t]{2}{*}{$\mathrm{p}$ - value } \\
\hline & Range & Mean \pm SD & Mean \pm SD & Range & \\
\hline Total proteins $\mathrm{g} \backslash \mathrm{dl}$ & $5.4-7.2$ & $6.39 \pm 0.5$ & $6.61 \pm 0.55$ & $5.8-7.5$ & 0.298 \\
\hline Albumin $\mathrm{g} \backslash \mathrm{dl}$ & $3.7-4.5$ & $4.1 \pm 0.27$ & $4.2 \pm 0.35$ & $3.7-4.7$ & 0.62 \\
\hline Direct biliubin $\mathrm{mg} \backslash \mathrm{dl}$ & $0.04-0.8$ & $0.15 \pm 0.23$ & $0.07 \pm 0.23$ & $0.04-0.12$ & 0.382 \\
\hline Total bilirubin $\mathrm{mg} \backslash \mathrm{dl}$ & $0.34-0.39$ & $0.36 \pm 0.17$ & $0.36 \pm 0.10$ & $0.29-0.64$ & 0.999 \\
\hline AST U U 1 & $50.0-93.3$ & $68.4 \pm 13.9$ & $65.6 \pm 10.6$ & $45.4-76.6$ & 0.762 \\
\hline ALT $\quad$ U 1 & $24.8-35.5$ & $30.0 \pm 3.8$ & $31.7 \pm 2.4$ & $28.2-35.9$ & 0.454 \\
\hline Alkaline Phosphatase U\l & $107-180$ & $150 \pm 30.3$ & $134 \pm 22.3$ & $97-160$ & 0.696 \\
\hline SOD $\quad$ U\ $100 \mathrm{mg}$ & 81.9108 .0 & $94 \pm 9.0$ & $144.7 \pm 17.1$ & $123.8-168.5$ & $\leq 0.000$ \\
\hline Catalase nmol $\backslash 100 \mathrm{mg}$ & $40.3-42.3$ & $41.6 \pm 0.69$ & $44.7 \pm 0.47$ & $44.0-45.4$ & 0.043 \\
\hline Glutathione nmol\100mg & $0.06-0.08$ & $0.07 \pm 0.005$ & $0.09 \pm 0.02$ & $0.06-0.13$ & 0.004 \\
\hline MDA nmol $\backslash 100 \mathrm{mg}$ & 38.4- 44.4 & $41.2 \pm 2.1$ & $32.1 \pm 2.2$ & $29.3-35.5$ & $\leq 0.000$ \\
\hline
\end{tabular}

The mean values of the total proteins, albumin, ALT, SOD, catalase and glutathione were increased in the experimental group compared to the control group. The decreased parameters in the experimental group were direct bilirubin, AST, alkaline phosphatase and MDA. The significant differences were seen when comparing the means of the antioxidant enzymes, glutahthione and MDA. The results showed the effectiveness of gum Arabic as an antioxidant compound. Its effect on the liver function was not significant.

Fig.1: Mean Concentration of Total Proteins, Albumin, Direct Bilirubin, Total Bilirubin and Glutathione in the Control and Experimental (gum Arabic treated) groups

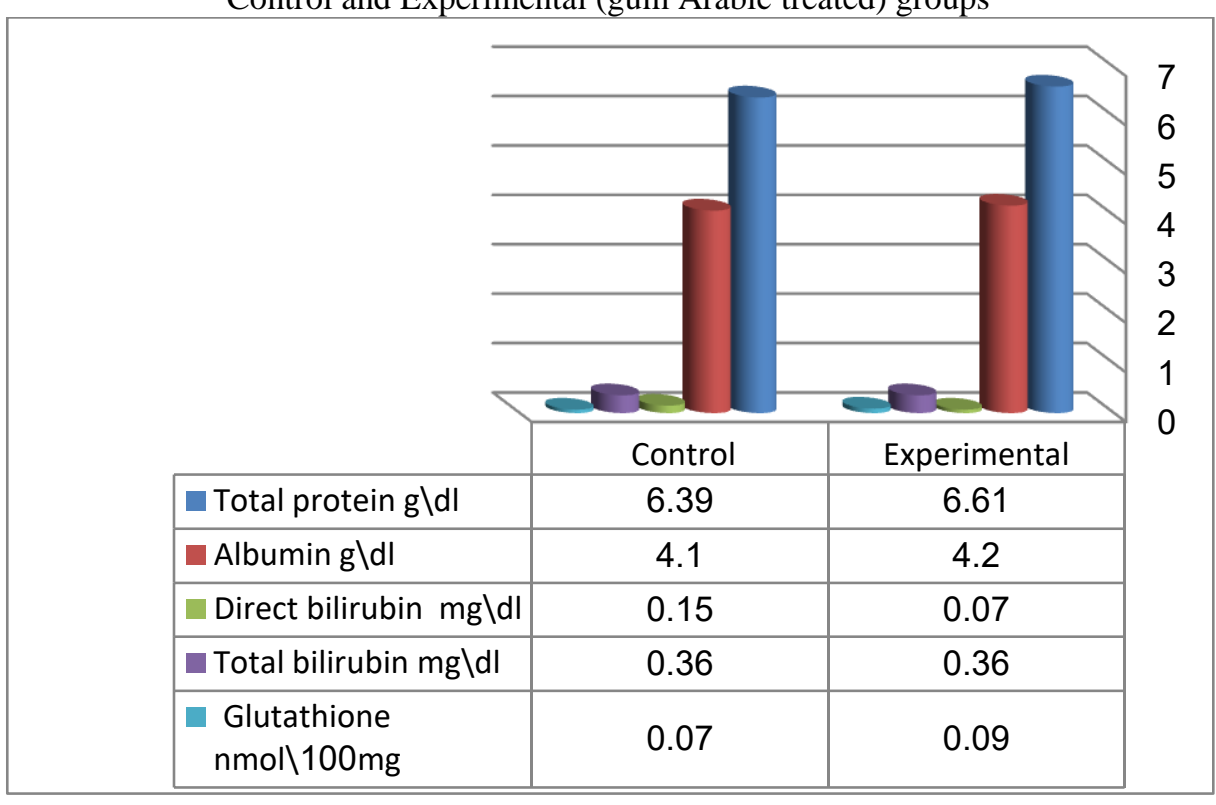

The total protein, albumin, direct bilirubin and total bilirubin were measured in the blood of the rats as liver function tests. The glutathione concentration was measured in $100 \mathrm{mg}$ of the rats liver. The mean concentration of the total proteins, albumin were insignificantly increased in the experimental group. The direct bilirubin was insignificantly decreased and the total bilirubin was not changed in the experimental group compared to the control group. The liver glutathione concentration in the experimental group was significantly increased $(\mathrm{p}$-value $=0.004)$. 
Fig.2: Mean Values of Liver Enzymes and MDA Concentration in the Control and Experimental (gum Arabic treated) groups

\begin{tabular}{|c|c|c|c|}
\hline & & $1<$ & \multirow[t]{8}{*}{$\begin{array}{l}160 \\
140 \\
120 \\
100 \\
80 \\
60 \\
40 \\
20 \\
0\end{array}$} \\
\hline & Control & Experimental & \\
\hline AST U\I & 68.4 & 65.6 & \\
\hline ALT U\I & 24.8 & 31.7 & \\
\hline Alkaline phosphatase U\I & 150 & 134 & \\
\hline SOD U\100mg & 94 & 144.7 & \\
\hline Catalase nmol\100mg & 41.6 & 44.7 & \\
\hline MDA nmol $\backslash 100 \mathrm{mg}$ & 41.2 & 32.1 & \\
\hline
\end{tabular}

The blood enzymes; aspartate trasnsaminase (AST), alanine transaminase ( ALT) and alkaline phosphatase were insignificantly changed in the experimental group compared to the control group. The enzymes measured in $100 \mathrm{mg}$ of liver tissues were superoxide dismutase (SOD) and the catalase, the two enzymes were significantly increased in the experimental group ( $p$ - values $\leq 0.000$ and $=0.043$ respectively). The malondialdehyde (MDA) was significantly decreased in the liver of the experimental groups ( $\mathrm{p}$-value $\leq$ 0.000). 